\title{
Different Patterns of Theory of Mind Impairment in Mild Cognitive Impairment
}

\author{
Noémie Moreau ${ }^{\mathrm{a}, \mathrm{b}, *}$, Stéphane Rauzy ${ }^{\mathrm{a}}$, Bernadette Bonnefoi ${ }^{\mathrm{b}}$, Laurent Reniéb, \\ Laurent Martinez-Almoyna ${ }^{\mathrm{b}}$, François Viallet ${ }^{\mathrm{a}, \mathrm{b}}$ and Maud Champagne-Lavau ${ }^{\mathrm{a}}$ \\ ${ }^{a}$ Aix-Marseille Université, CNRS, LPL UMR 7309, Aix-en-Provence, France \\ ${ }^{\mathrm{b}}$ Centre Hospitalier du Pays d'Aix, Department of Neurology, Aix-en-Provence, France
}

Accepted 17 December 2014

\begin{abstract}
Theory of Mind refers to the ability to infer other's mental states, their beliefs, intentions, or knowledge. To date, only two studies have reported the presence of Theory of Mind impairment in mild cognitive impairment (MCI). In the present study, we evaluated $20 \mathrm{MCI}$ patients and compared them with 25 healthy control participants using two Theory of Mind tasks. The first task was a false belief paradigm as frequently used in the literature, and the second one was a referential communication task, assessing Theory of Mind in a real situation of interaction and which had never been used before in this population. The results showed that MCI patients presented difficulties inferring another person's beliefs about reality and attributing knowledge to them in a situation of real-life interaction. Two different patterns of Theory of Mind emerged among the patients. In comparison with the control group, some MCI patients demonstrated impairment only in the interaction task and presented isolated episodic memory impairment, while others were impaired in both Theory of Mind tasks and presented cognitive impairment impacting both episodic memory and executive functioning. Theory of Mind is thus altered in the very early stages of cognitive impairment even in real social interaction, which could impact precociously relationships in daily life.
\end{abstract}

Keywords: Episodic memory, executive functions, mild cognitive impairment, social interaction, theory of mind

\section{INTRODUCTION}

In recent years, there has been a considerable increase in research on social cognition in neurodegenerative diseases. Social cognition is the ability to interpret and predict others' behavior and to decode social stimuli in the environment in order to adapt one's own behavior to social situations [1]. Theory of Mind (ToM) constitutes a central aspect of social cognition. It refers to the ability whereby an individual attributes mental states to himself and others, such as beliefs, intentions, or knowledge [2]. ToM impairments have been largely described in frontotemporal dementia ([3-11]; for reviews, see [12-14]) and in Alzheimer's

\footnotetext{
${ }^{*}$ Correspondence to: Noémie Moreau, Department of Neurology, CH Pays d'Aix, Laboratoire Parole et Langage, CNRS UMR 7309, Aix-Marseille Université, Avenue des Tamaris, 13616 Aixen-Provence, cedex 1 France. Tel.: +33 4423350 71; Fax: +33 4 423351 58; E-mail: nmoreau@ch-aix.fr.
}

disease $(\mathrm{AD})([5,6,8,15-20]$; for reviews, see [21, 22] $)$ during the past few years. In frontotemporal dementia, studies mostly focused on ToM difficulties in the early stages of the behavioral variant, in which executive functions could remain efficient. ToM was shown to be impaired in a wide variety of paradigms (e.g., first-order or second-order belief tasks, Faux-Pas task in which participants are asked to detect when someone does or says something inappropriately, or tasks requiring the understanding of lies, double-bluffing, pretending, or humor). In $\mathrm{AD}$, it was shown that high levels of ToM were impaired, even in the early stages of the disease, mostly in second-order belief tasks in which patients had to infer the mental state of a person about another person $[5,6,15,16,20]$. Some studies also reported impairment in more basic aspects of ToM such as gaze detection or first-order false belief tasks $[8,15,16]$. These ToM difficulties were discussed in relation to other cognitive dysfunctions, especially 
executive and memory domains [5, 6, 8, 15, 16, 19], despite the lack of sufficient statistical data to support this hypothesis. Indeed, the authors failed to determine if the patients' poor ToM performances were related to executive dysfunctions, impairing inferential reasoning about social situations, or if they were better explained by the complexity of the tasks. Only two studies have specifically addressed ToM ability in individuals with mild cognitive impairment (MCI) [23, 24]. MCI is a clinical entity which refers to the transitional condition between normal aging and dementia, most of the time dementia due to $\operatorname{AD}[25,26]$. More precisely, MCI is defined by mild cognitive deficit, whether or not it is limited to one cognitive domain, usually memory, with spared general cognitive functioning and preserved autonomy in daily life. MCI is considered a pre-dementia state carrying a high risk of conversion to dementia. In a complex second-order ToM task, it was shown that amnesic MCI patients were impaired when compared with healthy controls [23]. Amnesic MCI subjects were also impaired in inferring affective mental states [24] in the Reading the Mind in the Eyes Test [27]. However, they were similar to the controls in the Strange Stories task, in which they had to understand stories involving lies, double-bluffing, or pretending, in eye-gaze detection and in a first-order false belief task, in which they had to infer someone else's mental state [23]. Finally, without expressly assessing ToM, Gaudreau et al. [28] related the dulled understanding of verbal irony in amnesic single and multi-domain MCI patients to second-order ToM difficulties, despite the MCI group's high scores on the ToM question in their irony task. Significant correlations between ToM performances and some executive measures were found in Baglio et al. [23]. However, no correlation with episodic memory was reported in their study, while Poletti and Bonuccelli [24] reported some correlation. Overall, these results suggest that ToM impairment may arise in patients with spared general cognitive functioning and whose deficits are more isolated than in AD. Subtle changes in social behavior may thus be detected early in the pathological process. However, all these studies used standard artificial tasks, usually requiring complex verbal reasoning and high abilities in memory and executive domains. Moreover, these tasks do not assess ToM functioning in the context of real social interaction while it seems essential, particularly in pathological conditions, to gain a better understanding of the impact of ToM dysfunction on daily living.

Therefore, further research is required to fully characterize ToM impairment in MCI, notably in natural interactions, and to understand how difficulties in executive functions and episodic memory relate to ToM impairment (these cognitive domains are the most closely linked to ToM functioning [22, 29]). It could be hypothesized, for example, that early episodic memory dysfunction in MCI patients may have a precocious impact on ToM functioning, particularly in situations of real interaction. Moreau et al. [22] reviewed several results suggesting that mentalizing and remembering have common processes, notably the existence of a common neural substrate for both activities. Recent functional imaging studies reported the existence of a neuroanatomical overlap between remembering the past and thinking about others [30-35]. The description of this cerebral network included common midline structures, i.e., the medial prefrontal cortex, precuneus, posterior cingulate, and medial temporal lobe, and more lateral regions, i.e., inferior frontal gyrus, the temporal poles, and the temporo-parietal junction. Posterior cingulate and medial prefrontal cortex were shown to be particularly active during both activities, while some regions seemed to be preferentially dedicated to episodic memory or ToM $[22,36]$. It was hypothesized that the activation of this common cerebral network changes according to familiarity with the social situation. A higher degree of overlap has indeed been observed in ToM tasks involving familiar persons or situations [31,37]. This may indicate that memory plays an important role when we have already interacted with a person or if we have been in a similar social situation previously. Taking this into account, it can be assumed that engagement in real interaction may rely more on episodic retrieval, which is less the case in tasks involving reasoning about fictitious characters in fictitious situations.

Moreover, further evidence suggests that the underlying processes engaged when a person is actively involved in an interaction with someone (secondperson perspective) are different to these engaged when $\mathrm{s} /$ he is merely passively observing an interaction between two other people (third-person perspective), whether fictional or not [38-41]. In daily life, the attribution of mental states to others is most likely implicit and spontaneous, whereas standard ToM tests rely on slow, deliberate, cognitively-demanding reasoning about fictional characters' visions of reality [42]. Being actively involved or not in an interaction may considerably impact the participant's attribution of mental states with regard to environmental feedback and the current dynamic of interaction. Indeed, two people while interacting, have to constantly assess changes in their partners' faces, voices or discourse, 
in order to adapt their responses and behavior, which implies efficient ToM ability.

Using a referential communication paradigm is a relevant way to evaluate ToM in a natural situation of conversation [43]. This paradigm enables us to assess how interlocutors take into account, or fail to take into account, shared knowledge acquired in previous conversational exchanges [44]. In this task, a participant playing the role of a director is required to produce discriminating information that will enable the interlocutor to identify target figures. When the task is repeated several times with the same interlocutors and the same figures, a significant increase in communicative efficiency should be observed, reflecting the accumulating body of common knowledge between the two interlocutors. This task relies on the fact that linguistic markers of referential cohesion, such as indefinite (a mountain) or definite (the mountain) descriptions, play a primary role in marking the construction of shared-knowledge between interlocutors during an interaction and/or repeated exchanges [45]. These linguistic markers reveal the knowledge the speaker assumes to be shared by himself and the listener (this paradigm is detailed later in the method). As the task is repeated, healthy participants use increasingly definite descriptions to mark old, already known information and use less indefinite descriptions which would be expected in the introduction of new information [44]. The switch from indefinite to definite markers during the discourse indicates that the speaker is attributing to the listener specific knowledge which has been established in previous exchanges. Hence, these linguistic elements provide relevant and rigorous markers to determine the ability to judge, understand, and attribute mental states such as belief or shared knowledge (i.e., ToM) in a natural situation of conversation.

The main objective of the present study was to determine whether ToM impairment is detectable in MCI individuals using an ecological task enabling us to assess ToM during a natural conversation situation (i.e., paradigm of referential communication) compared to a more standard ToM task (i.e., false belief paradigm). Using these two different tasks involving different mechanisms may gather more evidence about the nature of ToM impairment in MCI. We expected that, compared to healthy control participants, MCI individuals would present difficulties in both ToM tasks, that is to say, not only in standard tasks, as demonstrated in previous studies, but also in a natural situation of conversation, showing that ToM impairment may occur at a very early stage in the pathological process. A secondary objective was to characterize the neuropsychological profile of the MCI individuals according to their ToM impairment.

\section{MATERIALS AND METHODS}

\section{Participants}

Twenty patients diagnosed with MCI and twentyfive healthy elderly control participants (HC) were included in this study. The controls were age-matched $(t(1,43)=-1.39, p>0.01)$ and educational level was equivalent $(t(1,43)=2.07, p>0.01)$. All participants were French native-speakers and had no history of psychiatric disorder. The MCI patients were recruited and consecutively enrolled in the memory unit of Aix-en-Provence Hospital. Each patient underwent a neurological and neuropsychological examination. The diagnosis of MCI was discussed in pluridisciplinary staff meeting and was based on Petersen's criteria [46]. More precisely, to be recruited, patients had to present a subjective cognitive complaint and had at least one domain of cognition below normal range of functioning. Their general intellectual functioning had to be preserved as assessed by the Mini-Mental State Examination (MMSE) [47] which should be $\geq 23$ to ensure they actually had MCI and that there was no dementia. Finally, family members were asked to fill out the Instrumental Activities of Daily Living questionnaire (eight areas of function) to verify that the patients were living independently and that daily activities were normally conducted. The exclusion criteria were 1) brutal onset of cognitive impairment, 2) history of another neurological disease as extrapyramidal signs, behavioral disorders, epilepsy, 3) history of vascular cerebral infarcts or severe white matter hyper intensity burden, 4) history of psychiatric illness, or 5) use of medical drugs known to have impact on cognitive functioning. The HC participants had no history of neurological or psychiatric disorder. Only control participants with a MMMSE score $\geq 27$ were selected to ensure they did not present any MCI. They were selected among relatives of patients of the Department of Neurology in Aix-en-Provence Hospital. HC and MCI participants had no problems with autonomy in their daily lives $(t(1,43)=2.06$, $p>0.01$ ). MCI patients had a lower MMSE score (range 23-29) compared to HC participants (range 27-30) $(t$ $(1,43)=7.01, p<0.0001)$. See Table 1 for demographical and neuropsychological data. All participants gave their written informed consent before recruitment. The study was approved by the regional independent ethics 
Table 1

Demographic and neuropsychological data of $\mathrm{HC}$ and MCI groups

\begin{tabular}{|c|c|c|c|c|c|}
\hline & & $\mathrm{HC}(n=25)$ & $\operatorname{MCI}(n=20)$ & \multirow[t]{2}{*}{$t$} & \multirow[t]{2}{*}{$p$ values } \\
\hline & & Mean $( \pm \mathrm{SD})$ & Mean $( \pm$ SD $)$ & & \\
\hline \multicolumn{2}{|l|}{ Age (Range) } & $\begin{array}{c}72.96(7.59) \\
(61-87)\end{array}$ & $\begin{array}{c}75.95(6.6) \\
(64-84)\end{array}$ & -1.39 & 0.17 \\
\hline Education (Range) & Number of years & $\begin{array}{c}12.52(4.11) \\
(5-17)\end{array}$ & $\begin{array}{c}9.70(5.01) \\
(5-20)\end{array}$ & 2.08 & 0.04 \\
\hline Autonomy & IADL & $7.92(0.40)$ & $7.45(1.05)$ & 1.89 & 0.05 \\
\hline General Cognitive Functioning & MMSE & $29.08(1.22)$ & $25.89(1.79)$ & 7.01 & $<0.0001$ \\
\hline \multirow[t]{5}{*}{ Episodic Memory } & FCSRT Total Free Recall & $27.96(6.68)$ & $19.20(7.45)$ & 4.16 & $<0.0001$ \\
\hline & FCSRT Total Recall & $46.40(2.22)$ & $41.75(4.76)$ & 4.04 & $<0.001$ \\
\hline & FCSRT Delayed Recall & $15.92(0.28)$ & $14.40(1.85)$ & 3.69 & $<0.01$ \\
\hline & Logical Memory Immediate Recall & $44.56(10.36)$ & $32.70(12.69)$ & 3.45 & $<0.01$ \\
\hline & Logical Memory Delayed Recall & $26.56(5.32)$ & $16.55(9.57)$ & 4.19 & $<0.001$ \\
\hline \multirow[t]{2}{*}{ Inhibition } & Stroop Interference Score (time) & $2.31(0.63)$ & $2.76(0.72)$ & -2.2 & 0.03 \\
\hline & Stroop Errors & $0.92(1.63)$ & $3.00(2.81)$ & -2.94 & $<0.01$ \\
\hline \multirow[t]{7}{*}{ Shifting } & TMT B (s) & $88.96(40.98)$ & $168.80(80.79)$ & -4.03 & $<0.001$ \\
\hline & TMT B-A (s) & $54.20(36.01)$ & $117.30(70.76)$ & -3.63 & $<0.001$ \\
\hline & TMT B Errors & $0.32(0.75)$ & $0.65(0.99)$ & -1.28 & 0.21 \\
\hline & Category Fluency & $32.24(7.38)$ & $24.20(7.94)$ & 3.51 & $<0.001$ \\
\hline & Letter Fluency & $19.80(6.31)$ & $15.10(7.38)$ & 2.30 & 0.03 \\
\hline & MCST Total Errors & $8.92(5.48)$ & $15.95(9.84)$ & -2.86 & $<0.01$ \\
\hline & MCST Perseverative Errors & $2.48(2.08)$ & $5.70(5.08)$ & -2.66 & $<0.01$ \\
\hline Planning & Zoo Map Test Score & $7.40(0.82)$ & $6.25(2.31)$ & 2.22 & 0.05 \\
\hline Working Memory & Letters-Numbers Sequences & $12.40(2.57)$ & $8.75(2.57)$ & 4.74 & $<0.0001$ \\
\hline
\end{tabular}

IADL, Instrumental Activities of Daily Living; MMSE, Mini-Mental State Examination; FCSRT, Free and Cued Selective Reminding Test; TMT, Trail Making Test; MCST, Modified Card Sorting Test.

committee (CPP Sud-Méditerranée, reference 13-64) and by the French Agency for Health Product Safety (ANSM, reference 2013-A00504-41).

\section{Neuropsychological assessment}

During neuropsychological examination, all participants were assessed on verbal episodic memory with the Free and Cued Selective Reminding Test [48] (total free recall, total recall, and delayed total recall) and the Logical Memory of Weschler Memory Scale [49] (immediate recall and delayed recall). Their executive functions were assessed with: 1) the Stroop-Victoria [50] with interference score and total number of errors considered as inhibition indexes; 2) the Trail Making Test [51] with part-B completion time, difference between part B and part A completion time and perseverative errors in part B as shifting indexes; 3) the Modified Card Sorting Test [51] with total number of errors and total number of perseverative errors as shifting indexes; 4) the category and letter fluency [51] with total number of words as shifting and word generation indexes; and 5) the Zoo Map Test [52] with part 1 score as planning index. Finally, working memory was assessed with LettersNumbers Sequences of the Weschler Memory Scale [49].

\section{ToM assessment}

ToM ability was assessed with two tasks. The first one was a standard false belief task [53] in which participants had to infer the belief of a character based on correct representation (true belief or TB) or incorrect representation (false belief or FB) of reality. The second task was an ecological task, i.e., a referential communication task, assessing ToM in a natural situation of conversation [43].

\section{The false belief task: Nosy-neighbor}

The stimuli were composed of non-verbal video clips in which a hand-drawn protagonist (the nosy neighbor) looks in through a window and watches a woman handling various objects and boxes. The participant was told that the nosy neighbor can see the woman when he is standing in front of the window, but that he cannot see her when he walks away from the window. Each trial was composed of three scenes. In the first scene, the nosy neighbor appears, stops in front of the window, and watches the woman put an object (e.g., a pizza) inside a container (e.g., a pizza box). In half of the trials, the object was what would be expected to be in the box (i.e., predictable condition, called TB1 or FB1 according to condition). In the 


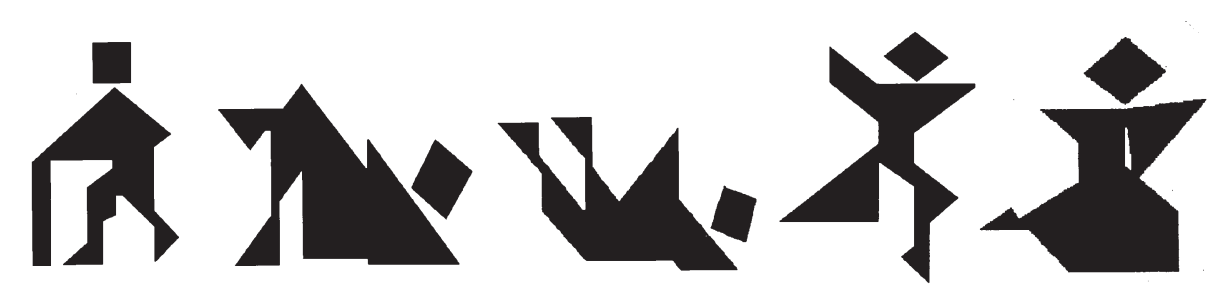

Fig. 1. Tangrams used for the Referential Communication Task.

other half of the trials, the contents of the box were not what would be expected (i.e., non predictable condition, called TB2 or FB2 according to condition). In the second scene, the woman replaces the first object by another one (e.g., the pizza is replaced by a passport) and the neighbor is either watching all the while in front of the window (TB condition) or has left the scene (FB condition). In half of the trials, the neighbor remains in front of the window watching the woman replacing the object (TB condition) and in the other half the neighbor leaves the scene while the object is replaced (FB condition). In the third scene, only the container was visible and the participant was asked to determine what the neighbor thinks is in the box. The participant was given an answer sheet showing the neighbor wondering about three possible answers, i.e., the contents that one would expected to be inside, given the type of container, and two other unrelated objects. Prior to the task, the participant underwent a pre-test in which s/he had to determine among three objects which one was the usual content of the boxes used in the task to ensure box recognition. There were eight trials for each condition (TB1, TB2, FB1, FB2) with a total of thirtytwo trials divided into two parts of sixteen trials each. According to Samson et al. [54], the design of this task allows us to discriminate different ToM impairment profiles given the type of errors a participant might make. A deficit in self-perspective inhibition would be characterized by a reality-based strategy in which participant would choose the last object put in the box, leading systematically to a reality-based error in false belief condition (FB1 and FB2) and a correct answer in true belief condition (TB1 and TB2). However, difficulty in inferring someone else's perspective would be characterized by an appearance-based strategy in which the participant would choose the object that usually corresponds with the container (appearance-based error). This strategy would lead to errors in both TB and FB condition (TB and FB2) according to the sequence of objects put in the box. Moreover, we can distinguish two other types of error. In strategy-based errors, the participant would choose the first object put in the box which would lead to errors in TB condition but a cor- rect answer in FB condition. Finally, distractor errors correspond to the object that was not present in the entire scene.

\section{The referential communication task}

In this task, the participant played a collaborative game with an experimenter. The stimuli were composed of the five tangrams used in Champagne-Lavau et al. [43] (Fig. 1). These figures have no a priori names and the participant had to find a way to refer to them. The participant and the experimenter were separated by an opaque screen in order to avoid non-verbal communication (gestures). The participant received the five figures in a given order on a sheet of paper. This order was unknown to the experimenter who had the same set of figures on individual cards which were laid out randomly. The participant, playing the role of director, was asked to describe the five tangrams from left to right in such a way as to help the experimenter, playing the role of addressee, arrange them in the correct order. The participant was told that both players had the same figures but in different orders and that they would play the game three times, each time with a new order of the figures. Thus, the participant needed to provide discriminating information in order to enable the experimenter to identify each figure. The experimenter took a neutral attitude and never suggested definite references concerning figures until the participant did. At the end of each trial, the participant and the experimenter checked to find out whether the experimenter's figures were in the same order as those of the participant. At the end of the task, the participant was asked if he could recognize the five figures which had been used in the task among five new tangrams which had not been seen before, to ensure that they remembered the form of the figures described. If the figures from the task were easily recognized, it could be assumed that any difficulties which may have been encountered in this task could not be related to an inability to remember previously encountered figures. The speech production was recorded and subsequently transcribed verbatim. For each trial (first, second and third) we 
measured: 1) the total number of words produced; 2) the number of speaking turns (defined as a sequence of speech with no interruption by the partner); and 3) the number of indefinite references (indefinite articles such as 'a mountain'). We decided to consider uniquely indefinite references since it was the best marker of the attribution of knowledge and belief to another person [43]. Given that the total number of words varied across the participants, a ratio of indefinite references/total words (or IND/words ratio) was calculated. The evolution of the IND/words ratio across the three trials revealed the participants' ability to attribute knowledge to their addressee.

\section{Statistical analysis}

Unpaired $t$-tests were used to explore the differences in the groups concerning the clinical and neuropsychological variables. To determine the differences in the groups in the false belief task, a 2-group (MCI, HC) $\mathrm{x}$ 2-condition (TB, FB) repeated-measures ANOVA was performed on the total number of correct responses. Focusing on errors, we compared the distribution of types of errors among the two groups with unpaired $t$ tests to see if the same types of errors had been made in both groups and if not, how the groups differed. Thus, for each participant we calculated the ratio of each type of error to the total number of errors in a given condition (e.g., number of appearance-based errors in TB condition/number of total errors in TB condition). We distinguished FB1 and FB2 conditions since they could lead to different types of errors. However, it was not relevant to distinguish TB1 and TB2 conditions. The data of the referential communication task was analyzed with 2-group (MCI, HC) x 3-trial (1st trial, 2nd trial, 3rd trial) repeated-measures ANOVAs on the total number of words produced, the number of speaking turns and the IND/words ratio. A hierarchical cluster analysis (Ward's method) was performed to explore different patterns of ToM performances in the MCI group. Given multiple testing, the alpha level was adjusted with the false discovery rate (FDR) method using Benjamini-Hochberg procedure. The adjusted alpha level was set at $p<0.01$ for all the analyses. All statistical analyses were performed with IBM SPSS Statistics 20.

\section{RESULTS}

\section{Neuropsychological characteristics}

The neuropsychological characteristics of both groups are presented in Table 1. MCI participants showed lower performances than $\mathrm{HC}$ participants in episodic memory: total free recall $(p<0.0001)$, total recall $(p<0.001)$, and delayed recall $(p<0.01)$ of the Free and Cued Selective Reminding Test, and the immediate recall $(p<0.01)$ and delayed recall $(p<0.001)$ of Logical Memory. They also obtained lower scores on several executive functions: Stroop interference errors $(p<0.01)$, Trail Making Test B time $(p<0.001)$, Trail Making Test B-A time $(p<0.001)$, category fluency $(p<0.001)$, Modified Card Sorting Test total errors $(p<0.01)$, and Modified Card Sorting Test perseverative errors $(p<0.01)$. The MCI participants had a poorer performance in working memory: letters-numbers sequences $(p<0.0001)$. No difference was found between groups on Stroop interference score $(p>0.01)$, Trail Making Test B errors $(p>0.01)$, letter fluency $(p>0.01)$, and Zoo Map Test score $(p>0.01)$ (cf. Table 1).

\section{ToM results}

\section{False belief task}

The $2 \times 2$ repeated-measures ANOVA on the total number of correct answers revealed a main effect of group $\left(F(1,43)=16.26, p<0.001, \eta_{\mathrm{p}}^{2}=0.27\right)$, showing that $\mathrm{HC}$ participants outperformed MCI patients whatever the condition. There was no effect of condition $(F(1,43)=0.27, p>0.01)$ and in the interaction group $\mathrm{x}$ condition was not significant $(F$ $(1,43)=1.12, p>0.01)$ (cf. Fig. 2). The unpaired $t$-test analyses on errors ratio showed that, compared to HC participants, MCI patients made significantly more appearance-based errors in TB $(p<0.01)$ and FB2 $(p<0.01)$ conditions. There were no differences for reality-based errors ratio in FB1 and FB2 conditions $(p>0.01)$. There was no difference between the groups in either strategy-based errors in TB condition $(p>0.01)$ or distractor errors ratio $(p>0.01)$.

\section{Referential communication task}

The results of the $2 \times 3$ repeated-measures ANOVA on the total number of words showed a main effect of trial $\left(F(2,84)=97.42, p<0.0001, \eta_{\mathrm{p}}^{2}=0.70\right)$, with a significantly higher number of words between the first and second trial $(p<0.0001)$, the second and the third trial $(p<0.0001)$, and the first and the third trial $(p<0.0001)$. There was also a main effect of group $\left(\mathrm{F}(1,42)=7.79, p<0.01, \eta_{\mathrm{p}}^{2}=0.16\right)$, the MCI participants producing more words than HC participants. The interaction group $\mathrm{x}$ trial was not significant $(\mathrm{F}(2$, $84)=0.14, p>0.01$ ). Thus, the total number of words 

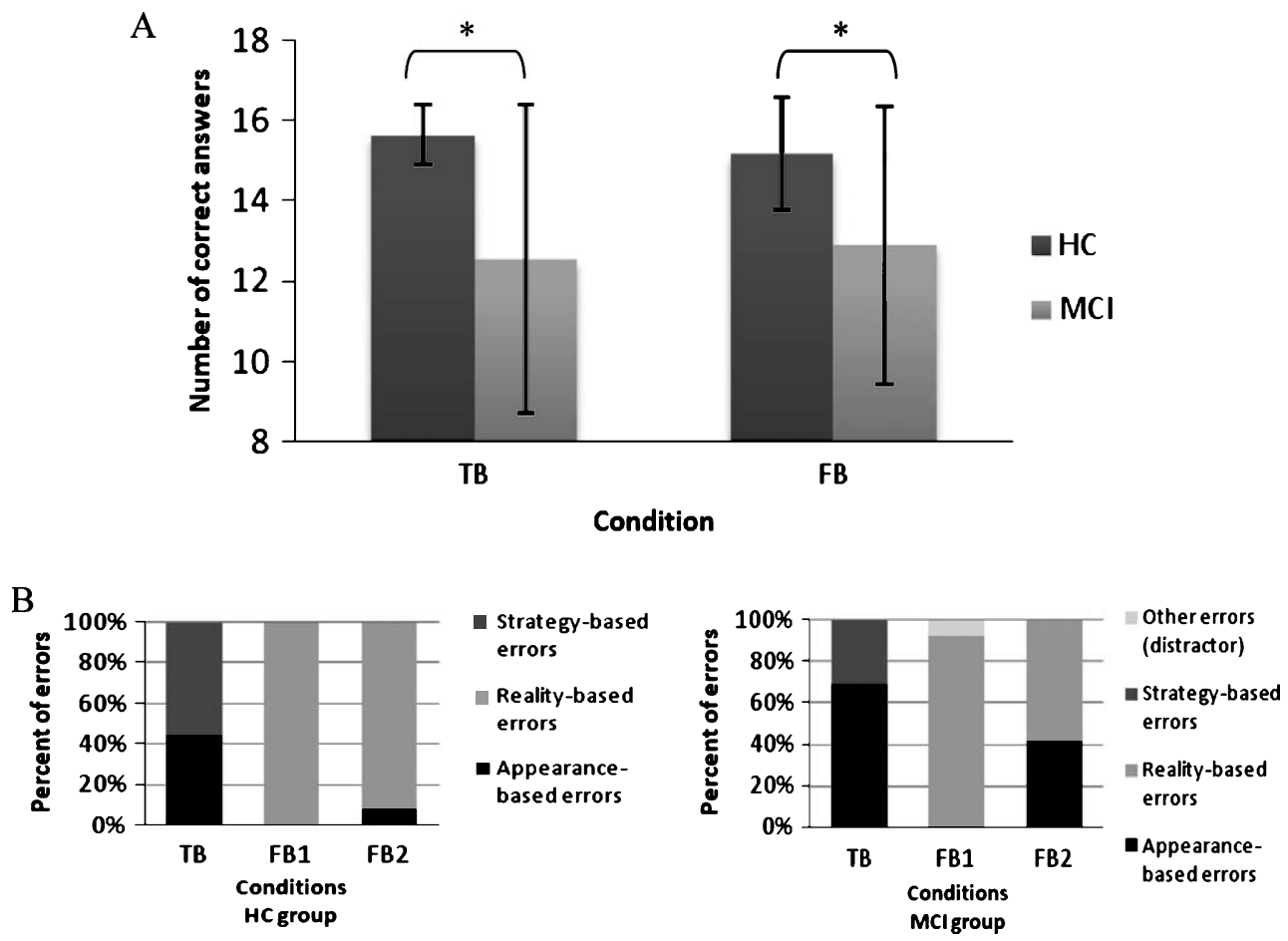

Fig. 2. A) Number of correct answers according conditions (TB, FB) and group (HC, MCI). B) Distribution of types of errors according conditions (TB, FB1, FB2) and group (HC, MCI). * significant differences. Abbreviations are: $\mathrm{TB}=$ true belief; $\mathrm{FB}=$ false belief.

A

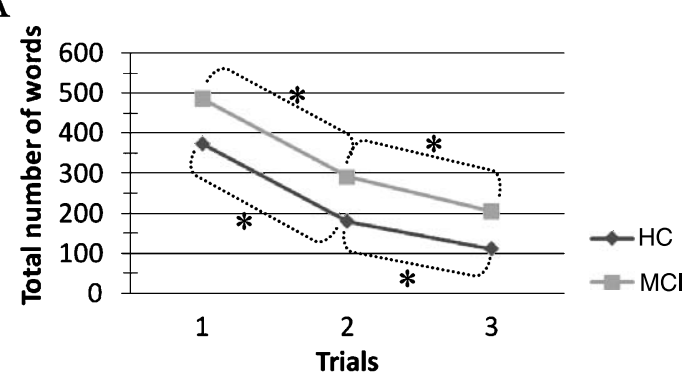

$\mathrm{C}$

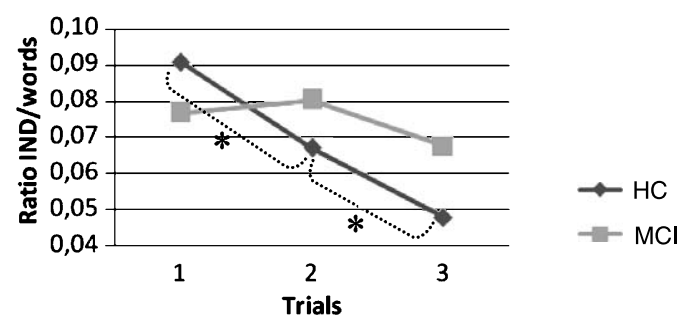

B

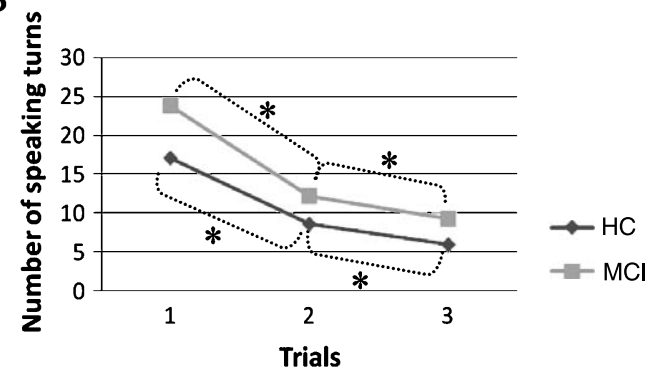

Fig. 3. A) Total number of words by trials for each group. B) Number of speaking turns by trials for each group. C) IND/words ratio by trials for each group. * significant differences.

used by participants decreased continuously from the first to the third trial in each group (cf. Fig. 3).

The results of the $2 \times 3$ repeated-measures ANOVA on the number of speaking turns showed a main effect of trial $\left(F(2,84)=69.50, p<0.0001, \eta_{\mathrm{p}}^{2}=0.62\right)$, with a significantly higher number of speaking turns between the first and second trial $(p<0.0001)$, the second and the third trial $(p<0.01)$, and the first and the third 
trial $(p<0.0001)$. Here again there was a main effect of group $\left(F(1,42)=8.16, p<0.01, \eta_{p}^{2}=0.16\right)$, the interactions requiring more speaking turns with $\mathrm{MCI}$ participants than with HC participants. The interaction group $\mathrm{x}$ trial was not significant $(\mathrm{F}(2,84)=1.39$, $p>0.01$ ) (cf. Fig. 3).

The results of the $2 \times 3$ repeated-measures ANOVA on the IND/words ratio showed a main effect of trial $(F$ $\left.(2,84)=11.36, p<0.0001, \eta_{\mathrm{p}}^{2}=0.21\right)$. The difference between the first and second trial was not significant $(p>0.01)$, while there were significant differences between the second and third trial $(p<0.01)$, as well as between the first and third trial $(p<0.001)$. There was no effect of group $(\mathrm{F}(1,42)=0.91, p>0.01)$. The interaction group $\mathrm{x}$ trial was significant $(F(2,84)=5.32$, $\left.p<0.01, \eta_{\mathrm{p}}^{2}=0.11\right)$. Interaction was decomposed by group. In the $\mathrm{HC}$ group, the results showed a significant difference between the first and second trial $(p<0.001)$ as well as between the second and third trial $(p<0.01)$, and the first and third trial $(p<0.0001)$. However, in the MCI group, there was no difference between the first and second trial $(p>0.01)$, the second and third trial $(p>0.01)$, and the first and third trial $(p>0.01)$. Thus, in the HC group, there was a continuous decrease of the number of indefinite references across the three trials which was not observed in the MCI group (cf. Fig. 3).

Finally, the participants of both groups recognized the tangrams described among new tangrams at the end of the task perfectly. There were no recognition errors among the MCI patients.

To sum up, the number of words and speaking turns decreased from the first to the third trial in both groups but the MCI participants needed more speaking turns and more words to describe tangrams whatever the trial. However, the MCI participants showed a different pattern in the use of indefinite markers during the task. While HC participants used less indefinite markers from trial to trial, MCI patients used the same number of indefinite markers from the beginning to the end of the task.

\section{Different patterns of ToM performance in MCI group}

In the MCI group, performances in the false belief task seemed heterogeneous. Some patients made a lot of errors while others made very few. Thus, a hierarchical cluster analysis (Ward's method) was undertaken on the MCI performances in the false belief task to determine whether different profiles exist among MCI participants. Two MCI subgroups of 10 participants were obtained suggesting two different profiles with one subgroup performing well $\left(\mathrm{MCI}^{+}\right)$and another making a lot of errors $\left(\mathrm{MCI}^{-}\right)$. One-way ANOVAs were performed on age, education, Instrumental Activities of Daily Living score, MMSE score, and all neuropsychological data to compare these two subgroups with each other and with the HC group. The results are presented in Table 2. The $\mathrm{MCI}^{+}$participants did not differ from the HC participants in terms of age $(p>0.01)$, education $(p>0.01)$, or autonomy $(p>0.01)$. $\mathrm{MCI}^{+}$patients were significantly different from HC participants on MMSE score $(p<0.0001)$, the three Free and Cued Selective Reminding Test's measures (total free recall $(p<0.01)$, total recall $(p<0.001)$, and delayed recall $(p<0.01))$, and the letters-numbers sequences $(p<0.01)$. The $\mathrm{MCI}^{+}$subgroup thus presented a cognitive deficit focused on episodic memory and working memory compared to $\mathrm{HC}$. The $\mathrm{MCI}^{-}$subjects were no different from HC participants in terms of age $(p>0.01)$ or autonomy $(p>0.01)$. However, they significantly differed from HC participants on educational level $(p<0.01)$, on the MMSE score $(p<0.0001)$, and in all measures of episodic memory, that is, total free recall $(p<0.01)$, total recall $(p=0.01)$, and delayed recall $(p<0.01)$ of the Free and Cued Selective Reminding Test, and immediate recall $(p<0.001)$ and delayed recall $(p<0.0001)$ of Logical Memory. They also differed from HC participants in several measures of executive functions, Stroop interference errors $(p<0.01)$, Trail Making Test-B time $(p<0.0001)$, Trail Making Test B-A time $(p<0.001)$, category fluency $(p<0.001)$, Modified Card Sorting Test total errors $(p<0.01)$, Modified Card Sorting Test perseverative errors $(p<0.01)$, and letters-numbers sequences $(p<0.001) . \mathrm{MCI}^{-}$participants thus presented a large cognitive impairment interesting several cognitive domains when compared to HC. Finally, the results showed no difference on all these variables $(p>0.01)$ between $\mathrm{MCI}^{+}$and $\mathrm{MCI}^{-}$groups (cf. Table 2).

Concerning ToM performances, a 3-group (HC, $\left.\mathrm{MCI}^{+}, \mathrm{MCI}^{-}\right) \times 2$-condition (TB, FB) repeatedmeasures ANOVA performed on the total number of correct answers in the false belief task revealed a main effect of group $(F(2,42)=63.01, p<0.0001$, $\left.\eta_{\mathrm{p}}^{2}=0.75\right)$. There was no effect of condition ( $\mathrm{F}(1$, $42)=0.03, p>0.01)$. The interaction group $\mathrm{x}$ condition was not significant $(F(2,42)=2.29, p>0.01)$, revealing that there was no difference between TB and FB conditions in either group (cf. Fig. 4). Posthoc test results showed that $\mathrm{MCI}^{+}$patients were no different from $\mathrm{HC}$ participants in either condition 
Table 2

Demographic and neuropsychological data of $\mathrm{MCI}^{+}$and $\mathrm{MCI}^{-}$subgroup

\begin{tabular}{|c|c|c|c|c|c|c|c|}
\hline & & $\begin{array}{c}\mathrm{HC}(n=25) \\
\text { Mean }( \pm \mathrm{SD})\end{array}$ & $\begin{array}{c}\mathrm{MCI}^{+} \\
(n=10) \\
\text { Mean }( \pm \mathrm{SD})\end{array}$ & $\begin{array}{c}\mathrm{MCI}^{-} \\
(n=10) \\
\text { Mean }( \pm \mathrm{SD})\end{array}$ & $\begin{array}{l}p \text { values } \mathrm{HC} \\
\text { versus } \mathrm{MCI}^{+}\end{array}$ & $\begin{array}{l}p \text { values } \mathrm{HC}^{-} \\
\text {versus } \mathrm{MCI}^{-}\end{array}$ & $\begin{array}{c}p \text { values } \mathrm{MCI}^{+} \\
\text {versus } \mathrm{MCI}^{-}\end{array}$ \\
\hline Age (Range) & & $72.96(7.59)(61-87)$ & $74.80(8.11)(64-84)$ & $77.10(4.82)(69-83)$ & 0.78 & 0.29 & 0.76 \\
\hline Education (Range) & Number of years & $12.52(4.11)(5-17)$ & $12.10(5.78)(5-20)$ & $7.30(2.58)(5-12)$ & 0.96 & $<0.01$ & 0.04 \\
\hline Autonomy & IADL & $7.92(0.40)$ & $7.20(1.32)$ & $7.70(0.68)$ & 0.04 & 0.71 & 0.30 \\
\hline General Cognitive Functioning & MMSE & $29.08(1.22)$ & $26.33(1.73)$ & $25.50(1.84)$ & $<0.0001$ & $<0.0001$ & 0.45 \\
\hline \multirow[t]{5}{*}{ Episodic memory } & FCSRT Total Free Recall & $27.96(6.68)$ & $19.20(9.41)$ & $19.20(5.33)$ & $<0.01$ & $<0.01$ & 1.00 \\
\hline & FCSRT Total Recall & $46.40(2.22)$ & $41.20(5.63)$ & $42.30(3.92)$ & $<0.001$ & 0.01 & 0.77 \\
\hline & FCSRT Delayed Recall & $15.92(0.28)$ & $14.40(2.12)$ & $14.40(1.65)$ & $<0.01$ & $<0.01$ & 1.00 \\
\hline & Logical Memory Immediate Recall & $44.56(10.36)$ & $37.40(14.21)$ & $28.00(9.42)$ & 0.21 & $<0.001$ & 0.15 \\
\hline & Logical Memory Delayed Recall & $26.56(5.32)$ & $20.00(11.85)$ & $13.10(5.13)$ & 0.05 & $<0.0001$ & 0.09 \\
\hline \multirow{2}{*}{ Inhibition } & Stroop Interference Score (time) & $2.31(0.63)$ & $2.59(0.70)$ & $2.93(0.74)$ & 0.52 & 0.05 & 0.50 \\
\hline & Stroop Errors & $0.92(1.63)$ & $2.20(1.55)$ & $3.80(3.58)$ & 0.27 & $<0.01$ & 0.24 \\
\hline \multirow[t]{7}{*}{ Shifting } & TMT B (sec) & $88.96(40.98)$ & $146.10(68.81)$ & $191.50(88.89)$ & 0.04 & $<0.0001$ & 0.23 \\
\hline & TMT B-A (sec) & $54.20(36.01)$ & $97.60(54.12)$ & $137.00(82.33)$ & 0.09 & $<0.001$ & 0.23 \\
\hline & TMT B Errors & $0.32(0.75)$ & $0.70(1.06)$ & $0.60(0.97)$ & 0.48 & 0.67 & 0.96 \\
\hline & Category Fluency & $32.24(7.38)$ & $27.80(9.66)$ & $20.60(3.31)$ & 0.25 & $<0.001$ & 0.08 \\
\hline & Letter Fluency & $19.80(6.31)$ & $16.00(6.60)$ & $14.20(8.34)$ & 0.31 & 0.09 & 0.83 \\
\hline & MCST Total Errors & $8.92(5.48)$ & $13.20(8.95)$ & $18.70(10.36)$ & 0.30 & $<0.01$ & 0.25 \\
\hline & MCST Perseverative Errors & $2.48(2.08)$ & $4.00(4.08)$ & $7.40(5.60)$ & 0.50 & $<0.01$ & 0.10 \\
\hline Planning & Zoo Map Test score & $7.40(0.82)$ & $6.10(2.33)$ & $6.40(2.41)$ & 0.11 & 0.26 & 0.92 \\
\hline Working Memory & Letters-Numbers Sequences & $12.40(2.57)$ & $9.20(1.93)$ & $8.30(3.13)$ & $<0.01$ & $<0.001$ & 0.72 \\
\hline
\end{tabular}

IADL, Instrumental Activities of Daily Living; MMSE, Mini-Mental State Evaluation; FCSRT, Free and Cued Selective Reminding Test; TMT, Trail Making Test; MCST, Modified Card Sorting Test. 
A

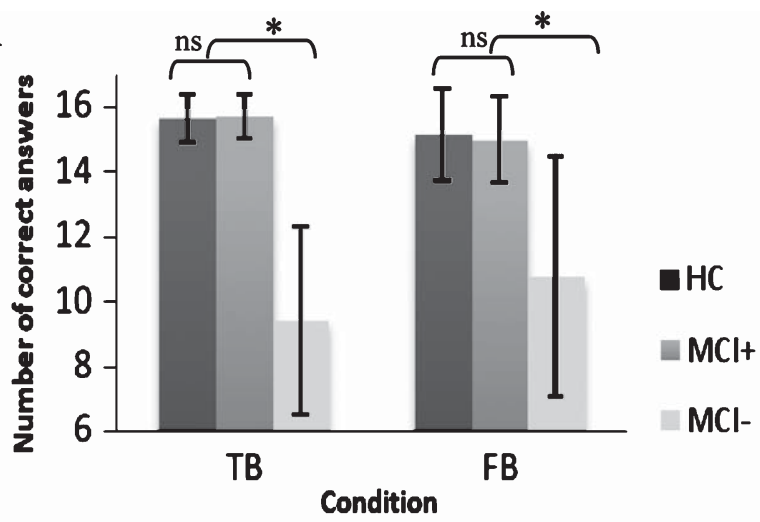

B
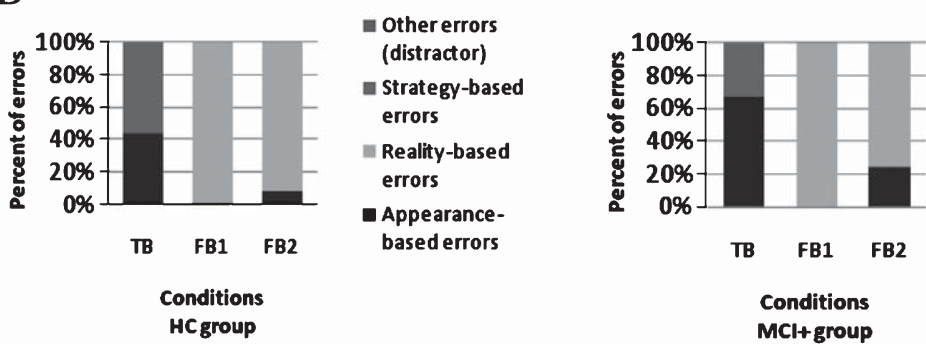

mether errors

I Strategy-based

errors

neality-based

errors

- Appearance-

based errors

Conditions
HC group

$\mathrm{MCl}+$ group

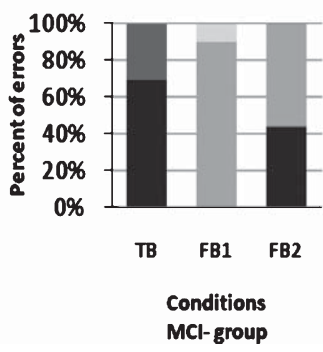

Other errors

(distractor)

- Strategy-based

errors

Reality-based

errors

- Appeareance-

based errors

Fig. 4. A) Number of correct answers according conditions (TB, $\mathrm{FB})$ and group $\left(\mathrm{HC}, \mathrm{MCI}^{+}, \mathrm{MCI}^{-}\right)$. B) Distribution of types of errors according conditions (TB, FB1, FB2) and group $\left(\mathrm{HC}, \mathrm{MCI}^{+}, \mathrm{MCI}^{-}\right)$. ns: no significant; ${ }^{*}$ significant differences; $\mathrm{Abbreviations}$ are: $\mathrm{TB}=$ true belief; $\mathrm{FB}$ $=$ false belief.

$(p>0.01)$. However, $\mathrm{MCI}^{-}$participants differed significantly from $\mathrm{HC}$ and $\mathrm{MCI}^{+}$groups in both $\mathrm{TB}$ and FB conditions $(p<0.0001)$.

We also compared the ratios of errors between groups with one-way ANOVA. Results revealed significant differences between groups on appearancebased errors in the TB condition $(\mathrm{F}(2,44)=25.03$, $p<0.0001)$, the FB2 condition $(\mathrm{F}(2,44)=12.68$, $p<0.0001)$ and on reality-based errors in FB1 condition $(\mathrm{F}(2,44)=5.35, p<0.01)$. Post hoc tests showed that there was no difference between the $\mathrm{MCI}^{+}$participants and $\mathrm{HC}$ participants $(p>0.01)$ in any type of error. The $\mathrm{MCI}^{+}$error profile was similar to that of the $\mathrm{HC}$ group. However, $\mathrm{MCI}^{-}$patients made significantly more appearance-based errors in TB $(p<0.0001)$ and
FB2 $(p<0.001)$ conditions compared to both HC and $\mathrm{MCI}^{+}$participants. They also differed only from $\mathrm{HC}$ participants in reality-based errors ratio in FB1 condition $(p<0.01)$. However, there was no difference in either strategy-based errors ratio in TB condition $(p>0.01)$ or the distractor errors ratio $(p>0.01)$.

In the referential communication task, the results of the $3 \times 3$ repeated-measures ANOVA on the total number of words showed a main effect of trial $(F(2$, $\left.82)=82.36, p<0.0001, \eta_{\mathrm{p}}^{2}=0.67\right)$, with a significantly higher number of words in the first trial compared to the second $(p<0.0001)$, in the second trial compared to the third trial $(p<0.0001)$, and the first trial compared to the third $(p<0.0001)$. There was also a main effect of group $\left(\mathrm{F}(2,41)=4.64, p=0.01, \eta_{\mathrm{p}}^{2}=0.19\right)$, the $\mathrm{MCI}^{+}$ 
A

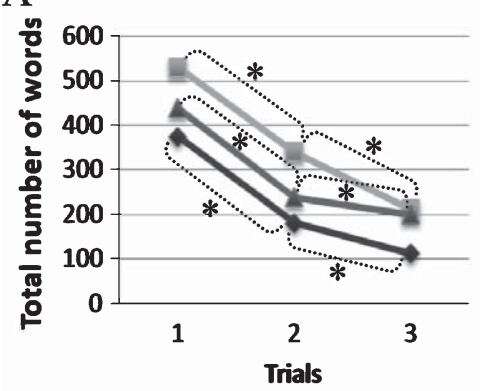

C

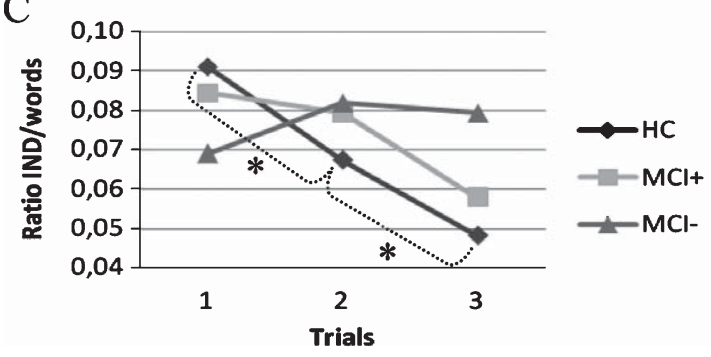

B

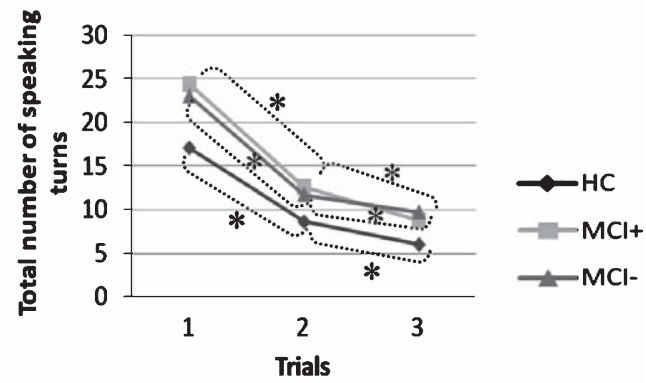

Fig. 5. A) Number of total words by trial for each group. B) Number of speaking turns by trial for each group. C) IND/words ratio by trial for each group. * significant differences.

participants producing more words than HC participants $(p=0.01)$. There was no difference between the $\mathrm{HC}$ and $\mathrm{MCI}^{-}$groups $(p>0.01)$ and between the $\mathrm{MCI}^{+}$ and $\mathrm{MCI}^{-}$groups $(p>0.01)$. The interaction group $\mathrm{x}$ trial was not significant $(F(4,82)=0.73, p>0.01)$. Thus, the total number of words used by the participants decreased continuously from the first to the third trial in every group. The $\mathrm{MCI}^{+}$subgroup used more words to describe tangrams than HC.

The results of the $3 \times 3$ repeated-measures ANOVA on the number of speaking turns showed a main effect of trial $\left(F(2,82)=61.78, p<0.0001, \eta_{\mathrm{p}}^{2}=0.60\right)$, with a significant higher number of speaking turns between the first and second trial $(p<0.0001)$, the second and the third trial $(p<0.01)$, and the first and the third trial $(p<0.0001)$. There was no main effect of group ( $\mathrm{F}(2$, $41)=4.00, p>0.01)$. The interaction group $\mathrm{x}$ trial was not significant $(F(4,82)=0.81, p>0.01)$. The number of speaking turns decreased from trial to trial whatever the group.

The results of the $3 \times 3$ repeated-measures ANOVA on the IND/words ratio showed a main effect of trial $\left(F(2,82)=5.93, p<0.01, \eta_{\mathrm{p}}^{2}=0.13\right)$. The difference between the first and second trial was not significant $(p>0.01)$, while there were significant differences between the second and third trial $(p<0.01)$, as well as between the first and third trial $(p<0.01)$. There was no main effect of group $(\mathrm{F}(2,41)=0.48, p>0.01)$. The interaction group $\mathrm{x}$ trial was significant $(F(4$, $\left.82)=4.06, p<0.01, \eta_{\mathrm{p}}^{2}=0.17\right)$. This interaction was considered by group. In the HC group, the results showed significant differences between the first and the second trial $(p<0.001)$, the second and the third trial $(p<0.01)$, and the first and the third trial $(p<0.0001)$. In the $\mathrm{MCI}^{+}$and $\mathrm{MCI}^{-}$subgroups, the results showed no difference between the first and the second trial $(p>0.01)$, the second and the third trial $(p>0.01)$, and the first and the third trial $(p>0.01)$. Thus, in the HC group, the IND/words ratio decreased continuously throughout the three trials, which was not true of the two MCI subgroups (Fig. 5).

To sum up, in comparison to the HC group, the MCI group showed impairment in both ToM tasks. Our analyses revealed two subgroups of patients. Firstly, in the false belief task the $\mathrm{MCI}^{+}$patients had equivalent scores to HC participants, making very few errors in each condition of the task. The IND/words ratio did not decrease throughout the trials as expected suggesting impairment in the referential communication task. These patients were characterized by a cognitive impairment restricted to memory with evidence of significant differences in several measures of episodic memory and working memory compared to the HC group. Secondly, $\mathrm{MCI}^{-}$patients were clearly impaired in the false belief task in both TB and FB conditions. These patients made significantly more appearancebased errors in TB and FB2 conditions in comparison to both $\mathrm{HC}$ and $\mathrm{MCI}^{+}$groups, and more reality-based 
errors in FB1 condition compared to $\mathrm{HC}$ participants. There was also evidence of their impairment in the referential communication task in which they could not be differentiated from $\mathrm{MCI}^{+}$subgroup. Compared to $\mathrm{HC}$, these patients were impaired in several domains of cognition with several measures of memory and executive functions affected.

\section{DISCUSSION}

The present study aimed to improve the characterization of ToM impairment in MCI compared with healthy elderly people. The main results showed that, as a whole, the MCI group presented a ToM deficit characterized by difficulties inferring someone's belief about reality and attributing knowledge to their interlocutor in a natural situation of conversation. Extended analysis revealed two different patterns of ToM impairment among the MCI group. ToM difficulties were more widespread in MCI participants impaired in several cognitive domains $\left(\mathrm{MCI}^{-}\right)$who failed in both TOM tasks, while MCI participants with isolated memory difficulties $\left(\mathrm{MCI}^{+}\right)$presented ToM impairment only in the referential communication task, when they took part in the interaction. Our results thus confirm previous studies showing the difficulties MCI patients have in mentalizing $[23,28]$. However, contrary to previous works, the present study is the first one to show impairment in mentalizing during natural conversation within a non-demented population, and to bring preliminary evidence of the heterogeneity of the ToM deficit amongst MCI patients.

\section{Differential patterns of ToM impairment in MCI}

Using two very different tasks allowed us to discriminate different patterns of ToM impairment in MCI patients. The $\mathrm{MCI}^{+}$subgroup only presented difficulties in the referential communication task, while they performed as well as healthy control participants in the standard ToM task. The way they referred to the tangrams was almost identical, using a majority of indefinite references throughout the trials as if not taking into account shared knowledge with the experimenter. As evidence of this, the ratio of indefinite markers did not decrease throughout the trials. In other words, patients ineffectively marked old information and continued to present figures as if they were being encountered by their interlocutor for the first time. This could not be related to the difficulty in remembering figures as the trials progressed, since the patients were able to recognize these same figures perfectly at the end of the task, picking them out from a group of figures including new tangrams. These results showed that the patients did not attribute knowledge acquired in previous exchanges (i.e., previous trials) to their partner. Contrary to the false belief task, the referential communication paradigm is a "second-person" perspective task involving the participant in the interaction. Our results thus provide more evidence to support the idea that ToM is not engaged in the same manner when a participant is involved in a social interaction with a real partner as when s/he is merely passively observing a fictitious interaction [38]. Impaired mentalizing in our $\mathrm{MCI}^{+}$patients arose in real-life, two-way interaction, when they had to integrate previous exchanges in order to adapt to the present interaction. These $\mathrm{MCI}^{+}$patients were essentially impaired in episodic memory compared to HC. This may suggest that this deficit could impact their ToM efficiency, with the hypothesis that behaving in any current interaction may be based on memories from previous interactions [22, 55]. This hypothesis is further supported by the results obtained in a similar referential paradigm with patients suffering from hippocampal amnesia, a form of amnesia which impairs episodic memory [56]. The authors showed that even if amnesic patients do construct a common body of references concerning a set of tangram figures when interacting with an interlocutor [57], they inadequately use definite references when referring to the figures. More precisely, amnesic patients were efficient in the way they labelled the figures, but were impaired in their capacity to refer to the common knowledge developed with their interlocutor concerning the figures. The authors concluded that the inconsistent use of reference markers throughout the task reveals difficulties in dealing with high-level discourse representations and managing shared knowledge and perspective (i.e., ToM) in relation to episodic memory disorders [56]. Thus, the possible relationship between episodic memory and ToM needs to be further explored, and preferably include correlation or regression analyses which could be conducted with a larger sample size.

On the other hand, the $\mathrm{MCI}^{-}$subgroup presented more widespread ToM impairment, not only in real interaction but also in a first-order false belief inference task. In the latter, they differed from both $\mathrm{HC}$ and $\mathrm{MCI}^{+}$participants on the total number of errors in both TB and FB conditions. More precisely, they made significantly more appearance-based errors in $\mathrm{TB}$ and $\mathrm{FB} 2$ conditions compared to $\mathrm{HC}$ and $\mathrm{MCI}^{+}$ participants, and more reality-based errors in FB1 compared to HC participants. The design of the task is 
such that errors in TB condition could also account for difficulties in mentalizing [53]. In appearancebased errors, the participant chooses the object that would be expected to go in the container, without taking into account the sequence of events, in order to attribute the correct mental state to the nosy neighbor. Samson et al. [53] considered that this strategy is not characteristic of a difficulty in inhibiting one's own perspective of reality (suggested by reality-based errors in FB condition), but rather that it is specific of a deficit in inferring the content of the mental state. In this case, the mentalizing judgment relies on a basic inference in which the participant states that the neighbor's belief is based on what he can see, i.e., the container. This may suggest that the answers which were inferred by the type of container could be representative of a difficulty to inhibit reality (the container representing reality for the participant when he sees it) and to understand that mental states (even true belief) can be different from what reality shows.

$\mathrm{MCI}^{-}$patients could not be distinguished from $\mathrm{MCI}^{+}$patients in any of the demographical or cognitive measures which we explored, probably because our sample size was not sufficient to evidence such differences. When compared with HC participants, $\mathrm{MCI}^{-}$patients appeared to be less educated. However, this probably does not account for their lower ToM performances since the range of educational levels was very extensive in both MCI subgroups, and some low-educated participants obtained high ToM performances in both subgroups (cf. scatterplots in Supplementary Material). $\mathrm{MCI}^{-}$also seemed to present a larger spectrum of cognitive disorders notably concerning executive functions. Can we therefore assume that their difficulty in realizing false belief inference may be related to their executive difficulties? As stated above, the false belief task is a "third-person" perspective task in which participants were not actively engaged in interaction with other agents but merely observed them in a video and were required to answer questions about characters' mental states. It requires slow, deliberate, and cognitively-demanding reasoning about a fictitious character's belief of reality. To provide the correct answer, the participants needed to maintain all the video sequences in working memory, to inhibit their own perspective of reality, and consider the correct point of view of the character concerning the content of the box. It is possible that the cognitive overload involved in conducting this task implies efficient executive functioning and may explain the fact that $\mathrm{MCI}^{-}$patients performed poorly in this task.
Both MCI subgroups presented working memory difficulties. This raises the question of its involvement in the ability to infer knowledge to an interlocutor in a social situation. According to Stone and Gerrans [58] and Samson [59], ToM is the result of low-level processes (i.e., eye gaze detection or facial emotion processing) interacting with high-level processes (i.e., long-term memory or executive functions). Samson's model proposes that inferred mental states are temporarily represented and maintained in working memory before being modulated by our social knowledge. Our results may thus be in favor of this hypothesis and give new evidence of a possible role for working memory in ToM.

\section{ToM deficit from MCI to dementia}

Our results provide more evidence that ToM difficulties may arise before dementia sets in, when patients' cognitive impairment is still relatively limited, which is consistent with previous studies [23, 24]. The novelty is that our results show evidence of ToM impairment in a natural conversation situation, close to everyday interactions, in MCI patients and that some of them could also present difficulties in executing a first-order ToM task. Subtle behavioral changes in social functioning could therefore be detected even in mildly cognitively impaired people whose general autonomy in daily living is spared. This may suggest that ToM naturally decreases with normal aging [60] and continues to worsen with pathological aging. In frontotemporal dementia, ToM was shown to be impaired whatever tasks were used, even in patients who had normal global cognitive functioning [3,5-7, 10]. This deficit is now considered one of the main features of the disease [61] as it may explain the early behavioral changes in personality and social conduct observed in patients. In $\mathrm{AD}$, ToM ability was shown to be altered in high levels of ToM (i.e., second-order tasks), but results concerning the tasks evaluating firstorder ToM are more contrasted [5, 6, 8, 15, 19, 20]. One study reported ToM deficit in AD with the falsebelief task we used here [8]. Their results showed that $\mathrm{AD}$ patients had a predominant deficit in inferring someone else's belief since they particularly committed appearance-based errors, as did our $\mathrm{MCI}^{-}$patients. Moreover, although they did not specifically assess ToM, Feyereisen and colleagues previously reported that AD patients had difficulty adequately using references shared with their interlocutor in a referential communication paradigm [62]. Like our MCI participants, AD patients continued to use the same number 
of indefinite markers all through the task, suggesting difficulty taking into account their interlocutor's knowledge.

MCI is by definition a heterogeneous condition, with impairment isolated to one cognitive domain (episodic memory or another cognitive function) or involving cognitive dysfunctions in several domains. It is an interesting model of pre-dementia but encompasses a wide range of patients with different patterns of cognitive dysfunction. It is now well accepted that some MCI patients will decline toward dementia after a number of years while others will remain stable [63-67]. MCI has been shown to be associated with a high risk of conversion to dementia particularly if subjects present a central amnesic deficit combined with dysfunctions in other domains of cognition [68]. From a neuroanatomical point of view, functional imaging studies have reported early connectivity abnormalities in specific cerebral regions in MCI, particularly in posterior cingulate, precuneus, hippocampus, and medial prefrontal cortex [69-74], regions involved in ToM or episodic memory [30-33]. Functional disturbances were reported as more extensive in MCI patients who convert to dementia with abnormalities very similar to those observed in $\mathrm{AD}$, while patients who remained stable over time had a pattern of cerebral connectivity comparable to that of the control participants [74]. In other words, patients with more widespread cerebral abnormalities may present more cognitive dysfunctions, especially in cognitive domains supported by these cerebral regions, which include ToM. In that way, subtle ToM deficits in MCI subjects may be related to the functional neuroanatomical abnormalities observed in early stages of pathological process [22]. It may therefore be suggested that an increasing ToM impairment may constitute a marker for the spread of functional abnormalities in the brain. In this sense, it could be a sensitive cognitive marker for the risk of conversion to clinically defined dementia. Undertaking longitudinal studies, supported by imaging, of MCI patients with impaired ToM could be a means of exploring this hypothesis further.

This study has a number of limitations. Firstly, a larger sample size is required to strengthen the results and the hypothesis we have drawn concerning other cognitive functions, in particular episodic memory, involved in ToM functioning. Secondly, as discussed earlier, MCI population is particularly heterogeneous. One benefit of assessing social cognition in a non-demented population is the possibility of characterizing different profiles of functioning in relation to a range of neurodegenerative outcomes. It could be very interesting to determine specific neuropathological conditions supported by analyses of biomarkers to characterize ToM profiles according to different neurodegenerative processes. A future study characterizing MCI patients a priori into single-domain versus multiple-domain impairment associated with biomarkers profile should thus be of great interest, as should longitudinal follow-up. ToM would be a novel cognitive tool to improve early diagnosis of dementia. The results of this study should thus be considered as preliminary, but it is the first work which demonstrated different patterns of ToM impairment in MCI patients.

\section{CONCLUSION}

This study is the first one to address ToM ability in MCI patients in conditions of natural interaction. It supports the presence of early mentalizing deficit arising in people with minor cognitive dysfunctions and totally preserved autonomy. If we take the group as a whole, the MCI patients present difficulties inferring someone's belief about reality and attributing knowledge to an interlocutor in a social interaction. Two different patterns of ToM were found among MCI patients in ToM performances. While MCI participants with isolated episodic memory dysfunction were only impaired when they took an active part in the interaction, the MCI participants with more widespread cognitive dysfunction had more extensive ToM impairment. These results may suggest that an increase in ToM impairment could be a reliable measure of risk of conversion to dementia. A longitudinal study assessing the ToM performances of MCI patients and whether or not there is conversion to dementia would be necessary to further address this hypothesis.

\section{ACKNOWLEDGMENTS}

This work was supported by an Agence Nationale de la Recherche grant (ANR-11-BSH2-006-01MINDPROGEST) to MCL.

Authors' disclosures available online (http://j-alz. com/manuscript-disclosures/14-3021).

\section{SUPPLEMENTARY MATERIAL}

The supplementary material is available in the electronic version of this article: http://dx.doi.org/10.3233/ JAD-143021. 


\section{REFERENCES}

[1] Adolphs R (2006) How do we know the minds of others? Domain-specificity, simulation, and enactive social cognition. Brain Res 1079, 25-35.

[2] Premack D, Woodruff G (1978) Does the chimpanzee have a theory of mind? Behav Brain Sci 4, 515-526.

[3] Bertoux M, Delavest M, de Souza LC, Funkiewiez A, Lépine J-P, Fossati P, Dubois B, Sarazin M (2012) Social Cognition and Emotional Assessment differentiates frontotemporal dementia from depression. J Neurol Neurosurg Psychiatry $\mathbf{8 3}$ 411-416.

[4] Eslinger PJ, Moore P, Troiani V, Antani S, Cross K, Kwok S, Grossman M (2006) Oops! Resolving social dilemmas in frontotemporal dementia. J Neurol Neurosurg Psychiatry $\mathbf{7 8}$, 457-460.

[5] Fernandez-Duque D, Baird JA, Black SE (2009) False-belief understanding in frontotemporal dementia and Alzheimer's disease. J Clin Exp Neuropsychol 31, 489-497.

[6] Gregory C, Lough S, Stone V, Erzinclioglu S, Martin L, Baron-Cohen S, Hodges JR (2002) Theory of mind in patients with frontal variant frontotemporal dementia and Alzheimer's disease: Theoretical and practical implications. Brain J Neurol 125, 752-764.

[7] Kipps CM, Nestor PJ, Acosta-Cabronero J, Arnold R, Hodges JR (2009) Understanding social dysfunction in the behavioural variant of frontotemporal dementia: The role of emotion and sarcasm processing. Brain 132, 592-603.

[8] Le Bouc R, Lenfant P, Delbeuck X, Ravasi L, Lebert F, Semah F, Pasquier F (2012) My belief or yours? Differential theory of mind deficits in frontotemporal dementia and Alzheimer's disease. Brain J Neurol 135, 3026-3038.

[9] Lough S, Kipps CM, Treise C, Watson P, Blair JR, Hodges JR (2006) Social reasoning, emotion and empathy in frontotemporal dementia. Neuropsychologia 44, 950-958.

[10] Torralva T, Kipps CM, Hodges JR, Clark L, Bekinschtein T, Roca M, Calcagno ML, Manes F (2007) The relationship between affective decision-making and theory of mind in the frontal variant of fronto-temporal dementia. Neuropsychologia 45, 342-349.

[11] Snowden JS, Gibbons ZC, Blackshaw A, Doubleday E, Thompson J, Craufurd D, Foster J, Happé F, Neary D (2003) Social cognition in frontotemporal dementia and Huntington's disease. Neuropsychologia 41, 688-701.

[12] Adenzato M, Cavallo M, Enrici I (2010) Theory of mind ability in the behavioural variant of frontotemporal dementia: An analysis of the neural, cognitive, and social levels. Neuropsychologia 48, 2-12.

[13] Cerami C, Cappa SF (2013) The behavioral variant of frontotemporal dementia: Linking neuropathology to social cognition. Neurol Sci 34, 1267-1274.

[14] Elamin M, Pender N, Hardiman O, Abrahams S (2012) Social cognition in neurodegenerative disorders: A systematic review. J Neurol Neurosurg Psychiatry 83, 1071-1079.

[15] Castelli I, Pini A, Alberoni M, Liverta-Sempio O, Baglio F, Massaro D, Marchetti A, Nemni R (2011) Mapping levels of theory of mind in Alzheimer's disease: A preliminary study. Aging Ment Health 15, 157-168.

[16] Cuerva AG, Sabe L, Kuzis G, Tiberti C, Dorrego F, Starkstein SE (2001) Theory of mind and pragmatic abilities in dementia. Neuropsychiatry Neuropsychol Behav Neurol 14, 153-158.

[17] Laisney M, Bon L, Guiziou C, Daluzeau N, Eustache F, Desgranges B (2013) Cognitive and affective Theory of Mind in mild to moderate Alzheimer's disease. J Neuropsychol 7, $107-120$.
[18] Verdon C-M, Fossati P, Verny M, Dieudonné B, Teillet L, Nadel J (2007) Social cognition: An early impairment in dementia of the Alzheimer type. Alzheimer Dis Assoc Disord 21, 25-30.

[19] Zaitchik D, Koff E, Brownell H, Winner E, Albert M (2004) Inference of mental states in patients with Alzheimer's disease. Cognit Neuropsychiatry 9, 301-313.

[20] Zaitchik D, Koff E, Brownell H, Winner E, Albert M (2006) Inference of beliefs and emotions in patients with Alzheimer's disease. Neuropsychology 20, 11-20.

[21] Kemp J, Després O, Sellal F, Dufour A (2012) Theory of Mind in normal ageing and neurodegenerative pathologies. Ageing Res Rev 11, 199-219.

[22] Moreau N, Viallet F, Champagne-Lavau M (2013) Using memories to understand others: The role of episodic memory in theory of mind impairment in Alzheimer disease. Ageing Res Rev 12, 833-839.

[23] Baglio F, Castelli I, Alberoni M, Blasi V, Griffanti L, Falini A, Nemni R, Marchetti A (2012) Theory of mind in amnestic mild cognitive impairment: An FMRI study. J Alzheimers Dis 29, 25-37.

[24] Poletti M, Bonuccelli U (2013) Alteration of affective Theory of Mind in amnestic mild cognitive impairment. J Neuropsychol 7, 121-131.

[25] Albert MS, DeKosky ST, Dickson D, Dubois B, Feldman HH, Fox NC, Gamst A, Holtzman DM, Jagust WJ, Petersen RC, Snyder PJ, Carrillo MC, Thies B, Phelps CH (2011) The diagnosis of mild cognitive impairment due to Alzheimer's disease: Recommendations from the National Institute on Aging-Alzheimer's Association workgroups on diagnostic guidelines for Alzheimer's disease. Alzheimers Dement 7, 270-279.

[26] Petersen RC, Roberts RO, Knopman DS, Boeve BF, Geda YE, Ivnik RJ, Smith GE, Jack CR (2009) Mild cognitive impairment: Ten years later. Arch Neurol 66, 1447-1455.

[27] Baron-Cohen S, Wheelwright S, Hill J, Raste Y, Plumb I (2001) The "Reading the Mind in the Eyes" Test revised version: A study with normal adults, and adults with Asperger syndrome or high-functioning autism. J Child Psychol Psychiatry 42, 241-251.

[28] Gaudreau G, Monetta L, Macoir J, Laforce R, Poulin S, Hudon C (2013) Verbal irony comprehension in older adults with amnestic mild cognitive impairment. Neuropsychology 27, 702-712.

[29] Aboulafia-Brakha T, Christe B, Martory M-D, Annoni J-M (2011) Theory of mind tasks and executive functions: A systematic review of group studies in neurology. J Neuropsychol 5, 39-55.

[30] Buckner RL, Carroll DC (2007) Self-projection and the brain. Trends Cogn Sci 11, 49-57.

[31] Rabin JS, Rosenbaum RS (2012) Familiarity modulates the functional relationship between theory of mind and autobiographical memory. Neuroimage 62, 520-529.

[32] Rabin JS, Gilboa A, Stuss DT, Mar RA, Rosenbaum RS (2010) Common and unique neural correlates of autobiographical memory and theory of mind. J Cogn Neurosci 22, 1095-1111.

[33] Spreng RN, Grady CL (2010) Patterns of brain activity supporting autobiographical memory, prospection, and theory of mind, and their relationship to the default mode network. J Cogn Neurosci 22, 1112-1123.

[34] Spreng RN, Mar RA (2012) I remember you: A role for memory in social cognition and the functional neuroanatomy of their interaction. Brain Res 1428, 43-50.

[35] Spreng RN, Mar RA, Kim ASN (2009) The common neural basis of autobiographical memory, prospection, navigation, 
theory of mind, and the default mode: A quantitative metaanalysis. J Cogn Neurosci 21, 489-510.

[36] Andrews-Hanna JR (2012) The brain's default network and its adaptive role in internal mentation. Neuroscientist 18, 251270.

[37] Perry D, Hendler T, Shamay-Tsoory SG (2011) Projecting memories: The role of the hippocampus in emotional mentalizing. Neuroimage 54, 1669-1676.

[38] Champagne-Lavau M, Moreau N (2013) Characteristics of current tasks that contribute to mentalizing judgments: Does the engagement of the participants in the social interaction matter? Comment on Achim et al. (2013). Psychol Assess 25, 1404-1406.

[39] De Bruin L, van Elk M, Newen A (2012) Reconceptualizing second-person interaction. Front Hum Neurosci 6, 151.

[40] De Jaegher H, Di Paolo E, Gallagher S (2010) Can social interaction constitute social cognition? Trends Cogn Sci 14, 441-447.

[41] Di Paolo E, De Jaegher H (2012) The interactive brain hypothesis. Front Hum Neurosci 6, 163.

[42] Frith CD (2012) The role of metacognition in human social interactions. Philos Trans R Soc B Biol Sci 367, 2213-2223.

[43] Champagne-Lavau M, Fossard M, Martel G, Chapdelaine C, Blouin G, Rodriguez J-P, Stip E (2009) Do patients with schizophrenia attribute mental states in a referential communication task? Cognit Neuropsychiatry 14, 217-239.

[44] Clark HH, Wilkes-Gibbs D (1986) Referring as a collaborative process. Cognition 22, 1-39.

[45] Pickering MJ, Garrod S (2004) Toward a mechanistic psychology of dialogue. Behav Brain Sci 27, 169-190.

[46] Petersen RC (2004) Mild cognitive impairment as a diagnostic entity. J Intern Med 256, 183-194.

[47] Folstein M, Folstein, Susan, McHugh Paul (1975) "Minimental state". A practical method for grading the cognitive state of patients for the clinician. J Psychiatr Res 12, 189-198.

[48] Van der Linden M, Coyette F, Poitrenaud J, Kalafat M, Calicis F, Wyns C, Adam S (2004) L'épreuve de rappel libre / rappel indicé à 16 items (RL/RI-16). In L'évaluation des troubles de la mémoire: Présentation de quatre tests de mémoire épisodique avec leur étalonnage. Solal, Marseille, pp. 25-47.

[49] Weschler D (1997) The Wechsler adult intelligence scale-third edition, Psychological Corporation, San Antonio.

[50] Moroni C, Bayard S (2009) Inhibitory process: What evolution after the age of 50? Psychol NeuroPsychiatr Vieil 7, 121-129.

[51] Godefroy O, Groupe de réflexion sur l'évaluation des fonctions, exécutives (2008) Fonctions exécutives et pathologies neurologiques et psychiatriques., Solal, Marseille.

[52] Wilson BA, Emslie H, Evans JJ, Alderman N, Burgess PW (1996) Behavioural Assessment of the Dysexecutive Syndrome, Thames Valley Test Company (TVTC), Bury St Edmunds, U.K.

[53] Samson D, Apperly IA, Humphreys GW (2007) Error analyses reveal contrasting deficits in "theory of mind": Neuropsychological evidence from a 3-option false belief task. Neuropsychologia 45, 2561-2569.

[54] Samson D, Apperly IA, Humphreys GW (2007) Error analyses reveal contrasting deficits in "theory of mind": Neuropsychological evidence from a 3-option false belief task. Neuropsychologia 45, 2561-2569.

[55] Spreng RN (2013) Examining the role of memory in social cognition. Front Psychol 4, 437.

[56] Duff MC, Gupta R, Hengst JA, Tranel D, Cohen NJ (2011) The use of definite references signals declarative memory:
Evidence from patients with hippocampal amnesia. Psychol Sci 22, 666-673.

[57] Duff MC, Hengst J, Tranel D, Cohen NJ (2006) Development of shared information in communication despite hippocampal amnesia. Nat Neurosci 9, 140-146.

[58] Stone VE, Gerrans P (2006) What's domain-specific about theory of mind? Soc Neurosci 1, 309-319.

[59] Samson D (2009) Reading other people's mind: Insights from neuropsychology. J Neuropsychol 3, 3-16.

[60] Duval C, Piolino P, Bejanin A, Eustache F, Desgranges B (2011) Age effects on different components of theory of mind. Conscious Cogn 20, 627-642.

[61] Rascovsky K, Hodges JR, Knopman D, Mendez MF, Kramer JH, Neuhaus J, van Swieten JC, Seelaar H, Dopper EGP, Onyike CU, Hillis AE, Josephs KA, Boeve BF, Kertesz A, Seeley WW, Rankin KP, Johnson JK, Gorno-Tempini M-L, Rosen H, Prioleau-Latham CE, Lee A, Kipps CM, Lillo P, Piguet O, Rohrer JD, Rossor MN, Warren JD, Fox NC, Galasko D, Salmon DP, Black SE, Mesulam M, Weintraub S, Dickerson BC, Diehl-Schmid J, Pasquier F, Deramecourt V, Lebert F, Pijnenburg Y, Chow TW, Manes F, Grafman J, Cappa SF, Freedman M, Grossman M, Miller BL (2011) Sensitivity of revised diagnostic criteria for the behavioural variant of frontotemporal dementia. Brain 134, 2456-2477.

[62] Feyereisen P, Berrewaerts J, Hupet M (2007) Pragmatic skills in the early stages of Alzheimer's disease: An analysis by means of a referential communication task. Int J Lang Commun Disord 42, 1-17.

[63] Fischer P, Jungwirth S, Zehetmayer S, Weissgram S, Hoenigschnabl S, Gelpi E, Krampla W, Tragl KH (2007) Conversion from subtypes of mild cognitive impairment to Alzheimer dementia. Neurology 68, 288-291.

[64] Palmer K, Fratiglioni L, Winblad B (2003) What is mild cognitive impairment? Variations in definitions and evolution of nondemented persons with cognitive impairment. Acta Neurol Scand 107, 14-20.

[65] Petersen RC, Negash S (2008) Mild cognitive impairment: An overview. CNS Spectr 13, 45-53.

[66] Petersen RC, Doody R, Kurz A, Mohs RC, Morris JC, Rabins PV, Ritchie K, Rossor M, Thal L, Winblad B (2001) Current concepts in mild cognitive impairment. Arch Neurol 58, 1985.

[67] Ward A, Tardiff S, Dye C, Arrighi HM (2013) Rate of conversion from prodromal Alzheimer's disease to Alzheimer's dementia: A systematic review of the literature. Dement Geriatr Cogn Disord Extra 3, 320-332.

[68] Palmer K, Bäckman L, Winblad B, Fratiglioni L (2008) Mild cognitive impairment in the general population: Occurrence and progression to Alzheimer disease. Am J Geriatr Psychiatry 16, 603-611.

[69] Bai F, Shi Y, Yuan Y, Wang Y, Yue C, Teng Y, Wu D, Zhang Z, Jia J, Zhang Z (2012) Altered self-referential network in resting-state amnestic type mild cognitive impairment. Cortex 48, 604-613.

[70] Bai F, Watson DR, Yu H, Shi Y, Yuan Y, Zhang Z (2009) Abnormal resting-state functional connectivity of posterior cingulate cortex in amnestic type mild cognitive impairment. Brain Res 1302, 167-174.

[71] Bai F, Zhang Z, Yu H, Shi Y, Yuan Y, Zhu W, Zhang X, Qian Y (2008) Default-mode network activity distinguishes amnestic type mild cognitive impairment from healthy aging: A combined structural and resting-state functional MRI study. Neurosci Lett 438, 111-115.

[72] Dickerson BC, Sperling RA (2008) Functional abnormalities of the medial temporal lobe memory system in mild cognitive 
impairment and Alzheimer's disease: Insights from functional MRI studies. Neuropsychologia 46, 1624-1635.

[73] Hafkemeijer A, van der Grond J, Rombouts SARB (2012) Imaging the default mode network in aging and dementia. Biochim Biophys Acta 1822, 431-441.
[74] Petrella JR, Sheldon FC, Prince SE, Calhoun VD, Doraiswamy PM (2011) Default mode network connectivity in stable vs progressive mild cognitive impairment. Neurology 76, 511-517. 